\title{
Influence of two stages (loading dose and maintenance dose) creatine supplementation on endogenous creatine synthesis during heavy-load exercise
}

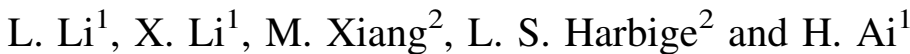 \\ ${ }^{1}$ Division of Nutrition and Biochemistry, Institute of Sports Medicine, The Third Hospital, Peking University, Beijing, \\ P.R. China and ${ }^{2}$ Centre for Biosciences Research, School of Science, University of Greenwich, Kent ME4 4TB, UK
}

Creatine (Cre), a natural nutrient found in animal foods, is alleged to be an effective nutritional ergogenic aid to enhance sport or exercise performance. Cre supplementation may enhance performance in certain repetitive, high-intensity, short-term exercise tasks ${ }^{(1,2)}$, and has not been prohibited by athletic governing bodies, so its use is currently regarded as legal. In humans, it is recommended to take Cre orally as a loading dose of $20 \mathrm{~g} / \mathrm{d}(0.3 \mathrm{~g} / \mathrm{kg} / \mathrm{d}, 67 \mathrm{~kg}$ body weight) for 5-7 days, followed by a long-term maintenance dose of $2-5 \mathrm{~g} / \mathrm{d}(0.03-$ $0.075 \mathrm{~g} / \mathrm{kg} / \mathrm{d})$. In rats, the doses of 1.5 and $0.15 \mathrm{~g} / \mathrm{kg} / \mathrm{d}$ were calculated from the recommended loading dose of $20 \mathrm{~g} / \mathrm{d}(0.3 \mathrm{~g} / \mathrm{kg} / \mathrm{d})$ and the maintainable dose of $2 \mathrm{~g} / \mathrm{d}(0.03 \mathrm{~g} / \mathrm{kg} / \mathrm{d})$ for human subjects according to Calabrese ${ }^{(3)}$. One of the adverse effects of Cre supplementation is that L-arginine:glycine amidinotransferase (L-AGAT), a key enzyme in the endogenous Cre synthesis in mammals, may be inhibited severely ${ }^{(4)}$. The present study has investigated the effect of supplementation with a loading dose $(1.5 \mathrm{~g}$ Cre/kg body weight per day) for 7 days and followed by a maintenance dose $(0.15 \mathrm{~g}$ Cre $/ \mathrm{kg}$ body weight per day) for 30 days or 60 days on the L-AGAT activity in the kidneys, the GAA concentration in the liver, and serum Cre and creatinine in swim-trained male Sprague-Dawley rats. L-AGAT activity and the GAA concentration were determined spectroscopically. Cre and creatinine in serum were also measured using an autoanalyser (7170A Hitachi Ltd., Japan). All rats were trained to swim for $4 \mathrm{~h} / \mathrm{d}$ and 6 days/week. On days 7, 37 and 67 (ten treatment and ten control rats per time point) after their respective supplementation period, L-AGAT activity and the GAA concentration decreased ( $\%)$ by $41.6 \%$ and $22.1 \%$ (Fig. A), and $56.2 \%$ and $21.3 \%$ (Fig. B), respectively, on days 7 and 37; however, there was no difference on days 67 when compared with their respective controls. No significant differences were found in the serum Cre and creatinine concentrations among the six groups.

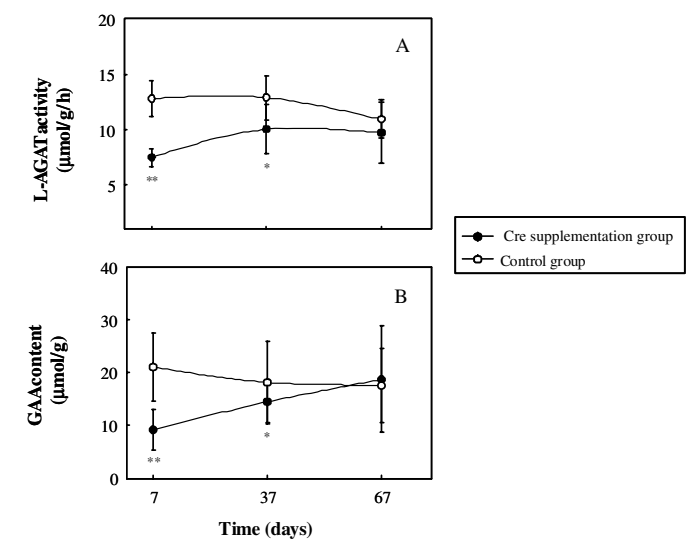

These findings indicate that in rats the reduction in L-AGAT activity and GAA concentration associated with supplementation with a loading dose $(1.5 \mathrm{~g}$ Cre/kg body weight per day) for 1 week could be reversed by changing supplementation with a maintenance dose $(0.15 \mathrm{~g} \mathrm{Cre} / \mathrm{kg}$ body weight per day), suggesting that short-term and high-dose Cre supplementation does not result in depression of endogenous Cre metabolism in heavy-load exercise body. As little is known about the effect of Cre supplementation on the immune system, investigation of the effect of long-term and high-dose Cre supplementation on endogenous Cre metabolism in immune cells of rats will be of interest.

1. Hespel P \& Derave W (2007) Subcell Biochem 46, 245-259.

2. Burke DG, Candow DG, Chilibeck PD et al. (2008) Int J Sport Nutr Exerc Metab 18, 389-398.

3. Calabrese EJ (1991) Principles of Animal Extrapolation, pp. 499-527. Chelsea, MI: Lewis Publishers Inc.

4. Wyss M \& Kaddurah-Daouk R (2000) Physiol Rev 80, 1107-1213. 